\title{
Partisipasi Petani dalam Penerapan Minapadi di Kabupaten Sleman
}

Farmers Participation In The Implementation Of Minapadi In Sleman Regency

\author{
Winda Ika Permatasari, Suwarto, Suminah
}

\author{
Program Studi Penyuluhan dan Komunikasi Pertanian Fakultas Pertanian \\ Universitas Sebelas Maret \\ Jl. Ir. Sutami No.36 A Kentingan Surakarta 57126 Telp/Fax (0271) 637457 \\ Email: windaikapermatasari@gmail.com
}

\begin{abstract}
This researchaims to examine the participation of farmers in the application of minapadi in Sleman Regency; examine the effect of non-formal education, experience, household income, paddy field area, group dynamics, and farming environment on farmer participation in the implementation of minapadi in Sleman Regency; and examine whether there are differences in farmer participation based on the farming environment in the application of minapadi in Sleman Regency. This research uses quantitative methods with survey techniques. The population in this study were farmers in the fish farmers group who received the Minapadi package program from the Agriculture, Food and Fisheries Service of Sleman Regency in Pakem District and Seyegan District. Samples using the Census method with 67 respondents as samples. Data analysis using multiple linear regression. The results of the study showed that the participation of farmers in the application of minapadi in Sleman Regency was in the moderate category. Participation factors simultaneously had a significant effect on farmer participation in the implementation of minapadi in Sleman Regency. Participation factors partially have a significant effect on farmer participation in the application of labor in the form of non-formal education, household income, and group dynamics while those that have no significant effect are experience, rice field area, and farming environment. There is no difference in farmer participation in implementing minapadi in Sleman Regency between upstream and downstream areas.
\end{abstract}

\section{Keyword: Minapadi, Participation, Farmers}

Abstrak: Penelitian ini bertujuan untuk mengkaji partisipasi petani dalam penerapan minapadi di Kabupaten Sleman, mengkaji pengaruh pendidikan non formal, pengalaman, pendapatan rumah tangga, luas lahan sawah, dinamika kelompok dan lingkungan usahatani terhadap partisipasi petani dalam penerapan mina padi di Kabupaten Sleman dan mengkaji perbedaan partisipasi petani berdasarkan lingkungan usahatani dalam penerapan minapadi di Kabupaten Sleman. Penelitian ini menggunakan metode kuantitatif dengan teknik survei. Populasi dalam penelitian ini adalah petani kelompok pembudidaya ikan yang mendapatkan program paket minapadi dari Dinas Pertanian, Pangan dan Perikanan Kabupaten Sleman di Kecamatan Pakem dan Kecamatan Seyegan. Sampel menggunakan metode Sensus dengan jumlah sampel petani responden sebanyak 67 orang. Analisis data menggunakan regresi linear berganda. Hasil penelitian menunjukkan bahwa partisipasi petani dalam penerapan minapadi di Kabupaten Sleman tergolong dalam kategori sedang. Faktor-faktor partisipasi secara serentak berpengaruh signifikan dalam partisipasi petani dalam penerapan minapadi di Kabupaten Sleman. Faktor-faktor partisipasi secara parsial berpengaruh signifikan terhadap partisipasi petani dalam penerapan minapadi yaitu pendidikan non formal, pendapatan rumah tangga dan dinamika kelompok sedangkan yang tidak berpengaruh signifikan yaitu pengalaman, luas lahan sawah dan lingkungan usahatani. Tidak terdapat perbedaan partisipasi petani dalam penerapan minapadi di Kabupaten Sleman antara di daerah hulu dan di daerah hilir.

Kata Kunci: Minapadi, Partisipasi, Petani 


\section{PENDAHULUAN}

Sektor pertanian merupakan salah satu sektor yang menjadi pusat perhatian dalam pembangunan nasional. Sektor pertanian memiliki kontribusi pada Produk Domestik Bruto (PDB) Indonesia. Produk Domestik Bruto (PDB) per kapita Indonesia pada tahun 2016 sebesar 6,25\% naik menjadi 8,1\% pada tahun 2017 (Badan Pusat Statistik, 2017). Kontribusi sektor pertanian khususnya di Daerah Istimewa Yogyakarta dapat dilihat dari luas panen, produksi dan produktivitas padi. Badan Pusat Statistik (2015) mencatat terdapat penurunan produktivitas padi terjadi pada tahun 2010 mencapai $61,35 \mathrm{kw} / \mathrm{ha}$ tetapi tahun 2011 terjadi penurunan lagi mencapai 59,82 $\mathrm{kw} / \mathrm{ha}$.

Penurunan hasil produktivitas padi tersebut salah satu penyebabnya adalah kondisi alih fungsi lahan. Menurut Dinas Pertanian Daerah Istimewa Yogyakarta (2017) laju alih fungsi lahan di Daerah Istimewa Yogyakarta tergolong cukup tinggi hingga terjadi penyusutan lahan sawah sebesar 1.199 Ha. Permasalahan keterbatasan lahan pertanian sebagai akibat dari alih fungsi lahan dapat dilakukan dengan konsep minapadi. Kabupaten Sleman merupakan wilayah yang menjadi lokasi percontohan usaha mina padi yang ditunjuk oleh FAO

(Food and Agriculture Organization) pada tahun 2015. Pemerintah Kabupaten Sleman mendukung penerapan minapadi yang mulai diperkenalkan dan menargetkan luas minapadi bertambah dari 108 ha menjadi 128 ha.

Pelaksanaan minapadi di Kabupaten Sleman tidak terlepas dari partisipasi petani. Keberhasilan penerapan minapadi ini ditentukan oleh salah satu faktor penting yaitu partisipasi petani. Menurut Dinas Pertanian, Pangan dan Perikanan Kabupaten Sleman (2017) mengalami penurunan jumlah petani minapadi pada tahun 2016 sebanyak 5.560 orang tetapi pada tahun 2017 menurun menjadi 720 orang. Kecamatan Pakem dan Kecamatan Seyegan merupakan Kecamatan yang sudah menerapkan minapadi yang terletak di daerah hulu dan daerah hilir. Keberlanjutan paket program minapadi tersebut belum baik, karena ketika petani tidak diberikan bantuan maka keaktifan dan partisipasi dari petani berkurang. Terbukti dari luasan lahan yang mereka usahakan berkurang dan petani masih sulit menerapkan minapadi secara swadaya atau mandiri.

Keberhasilan program minapadi memerlukan partisipasi yang tinggi dari para petani. Tingginya partisipasi tersebut akan membantu keberlanjutan penerapan minapadi secara terus menerus yang diterapkan baik pada tahap perencanaan, pelaksanaan, pemanfaatan hasil dan evaluasi.

\section{METODE PENELITIAN}

Penelitian ini menggunakan metode dasar kuantitatif dengan teknik survey. Lokasi penelitian yang diambil adalah Kecamatan Pakem dan Kecamatan Seyegan karena letaknya yang berada di daerah hulu $(43,84 \mathrm{mdpl})$ dan hilir (26,63 mdpl). Dua kecamatan tersebut dipilih untuk lokasi penelitian karena pernah mendapat bantuan program minapadi dari Dinas Pertanian, Pangan dan Perikanan Kabupaten Sleman serta sudah pernah menjadi percontohan oleh FAO (Food and Agriculture Organization). Populasi dari penelitian ini adalah petani kelompok pembudidaya ikan di Kecamatan Pakem dan Kecamatan Seyegan. Kecamatan Pakem terdapat 4 kelompok pembudidaya ikan dan Kecamatan Seyegan terdapat 3 kelompok pembudidaya ikan. Jumlah sampel petani responden pada penelitian ini adalah sebanyak 67 responden yang diambil secara sensus. Penelitian ini menggunakan jenis data kuantitatif dan data kualitatif. Sumber data yang digunakan pada penelitian ini adalah sumber data primer dan data sekunder yang diambil dengan cara wawancara, observasi, dokumentasi dan pencatatan. Penelitian ini menggunakan uji validitas dan reliabilitas untuk menguji kuisioner. Uji validitas menggunakan korelasi Pearson dilakukan terhadap 30 responden dengan $r$ tabel 0,361 dibandingkan dengan nilai $r$ hitung. Uji reliabilitas diperoleh nilai cronbach's alpha 0,957 berarti lebih besar dari 0,60 , sehingga kuisioner bisa dikatakan reliabel. Penelitian ini menggunakan uji regresi linear berganda, dilengkapi beberapa uji seperti uji asumsi klasik (uji normalitas, uji multikolonieritas dan uji heterokedastisitas) serta pengujian hipotesis (Uji F, uji t, dan $R^{2}$ ). 


\section{HASIL DAN PEMBAHASAN}

\section{Keadaan Umum Lokasi Penelitian}

Kabupaten Sleman merupakan salah satu dari kabupaten yang terletak di Daerah Istimewa Yogyakarta. Luas wilayah Kabupaten Sleman mencapai $574,82 \mathrm{~km}^{2}$ dengan jumlah penduduk 1.193.512 jiwa. Kecamatan Seyegan memiliki jumlah total penduduk yaitu 49.845 jiwa dan Kecamatan Pakem memiliki jumlah total penduduk 36.806 jiwa.Kecamatan Pakem dan Kecamatan Seyegan merupakan dua kecamatan di Kabupaten Sleman yang memiliki tingkat pendidikan sebagian besar SMA. Komoditas tanaman pangan paling banyak di dua kecamatan tersebut adalah padi sawah. Produksi ikan tertinggi di Kecamatan Pakem jenis ikan nila mencapai $3.623 \mathrm{kw}$, sedangkan di Kecamatan Seyegan jenis ikan lele mencapai $22.688,5 \mathrm{kw}$.

\section{Partisipasi Petani dalam Penerapan Minapadi}

Tabel 1.Distribusi Petani Berdasarkan Partisipasi terhadap Penerapan Minapadi

\begin{tabular}{|c|c|c|c|c|}
\hline \multirow{2}{*}{ TahapanPartisipasi } & \multirow{2}{*}{ Kategori } & \multirow{2}{*}{ Skor } & \multicolumn{2}{|c|}{ Distribusi } \\
\hline & & & Orang & $\%$ \\
\hline \multirow[t]{6}{*}{ Perencanaan } & SangatTinggi & $43,28-51,59$ & 0 & 0,00 \\
\hline & Tinggi & $34,96-43,27$ & 21 & 31,35 \\
\hline & Sedang & $26,64-34,95$ & 22 & 32,83 \\
\hline & Rendah & $18,32-26,63$ & 22 & 32,83 \\
\hline & SangatRendah & $10,00-18,31$ & 2 & 2,99 \\
\hline & Jumlah & & 67 & 100,00 \\
\hline \multirow[t]{6}{*}{ Pelaksanaan } & SangatTinggi & $37,40-44,49$ & 0 & 0,00 \\
\hline & Tinggi & $30,30-37,39$ & 21 & 31,35 \\
\hline & Sedang & $23,20-30,29$ & 28 & 41,79 \\
\hline & Rendah & $16,10-23,19$ & 16 & 23,87 \\
\hline & SangatRendah & $9,00-16,09$ & 2 & 2,99 \\
\hline & Jumlah & & 67 & 100,00 \\
\hline \multirow[t]{6}{*}{ Pemanfaatan Hasil } & SangatTinggi & $36,97-43,93$ & 4 & 5,97 \\
\hline & Tinggi & $30,00-36,96$ & 27 & 40,30 \\
\hline & Sedang & $22,94-29,90$ & 23 & 34,33 \\
\hline & Rendah & $15,97-22,93$ & 13 & 19,40 \\
\hline & SangatRendah & $9,00-15,96$ & 0 & 0,00 \\
\hline & Jumlah & & 67 & 100,00 \\
\hline \multirow[t]{6}{*}{ Evaluasi } & SangatTinggi & $44,12-52,64$ & 2 & 2,99 \\
\hline & Tinggi & $35,59-44,11$ & 24 & 35,82 \\
\hline & Sedang & $27,06-35,58$ & 22 & 32,83 \\
\hline & Rendah & $18,53-27,05$ & 19 & 28,36 \\
\hline & SangatRendah & $10,00-18,52$ & 0 & 0,00 \\
\hline & Jumlah & & 67 & 100,00 \\
\hline \multirow[t]{6}{*}{ Partisipasi Total } & SangatTinggi & $167,55-199,93$ & 0 & \\
\hline & Tinggi & $135,16-167,54$ & 18 & 26,86 \\
\hline & Sedang & $102,77-135,15$ & 33 & 49,25 \\
\hline & Rendah & $70,39-102,76$ & 16 & 23,89 \\
\hline & SangatRendah & $38,00-70,38$ & 0 & 0,00 \\
\hline & Jumlah & & 67 & 100,00 \\
\hline
\end{tabular}

Sumber : Analisis Data Primer, 2019 
Partisipasi petani pada tahap perencanaan dalam penerapan minapadi tergolong dalam kategori sedang dan rendah berjumlah sama dimana masing-masing berjumlah 22 orang atau mencapai $32,83 \%$. Pada kegiatan seperti sosialisasi minapadi yang diselenggarakan oleh Dinas Pertanian Kabupaten Sleman, petani yang hadir hanya perwakilan kelompok. Tidak semua anggota kelompok mendapatkan undangan namun hasil dari sosialisasi akan di sebarluaskan oleh perwakilan kelompok yang menghadiri sosialisasi tersebut. Kegiatan demplot yang dilakukan memusat di satu kelompok dan kegiatan pelatihan hanya diikuti oleh perwakilan dari kelompok. Petani mengajukan ide atau gagasan dalam rapat perencanaan penerapan minapadi atas kesadaran sendiri tanpa pengaruh dari orang lain. Terdapat petani yang masih enggan dan tidak mau mengajukan pendapatnya, sehingga petani kurang dapat mengungkapkan ide atau gagasan serta adanya sikap pasrah dan ikut-ikutan dengan pendapat orang lain.

Partisipasi pada tahap pelaksanaan kegiatan yaitu keikutsertaan petani secara langsung dalam penerapan minapadi. Partisipasi petani pada tahap pelaksanaan dalam penerapan minapadi tergolong dalam kategori sedang mencapai $41,79 \%$ atau dengan jumlah 28 orang. Hasil di lokasi penelitian menunjukkan bahwa belum semua petani menerapkan minapadi sesuai dengan SOP yang sudah ditentukan. Hal ini terjadi karena keadaan wilayah mempengaruhi sehingga tidak dapat berjalan sesuai dengan SOP. Banyak petani yang masih berfikir kolot apabila menggunakan minapadi akan banyak memakan lahan sawah khususnya untuk pembuatan kolam dalam maupun caren. Kurang maksimalnya pada tahap pelaksanan ini berdampak pada produksi ikan maupun padi yang akan diperoleh petani.

Partisipasi pada tahap pemanfaatan hasil yaitu sejauh mana petani merasakan manfaat atau hasil dari penerapan minapadi. Partisipasi petani pada tahap pemanfaatan hasil dalam penerapan minapadi tergolong dalam kategori tinggi mencapai $40,30 \%$ atau dengan jumlah 27 orang. Hasil di lokasi penelitian menunjukkan bahwa petani merasa dengan penerapan minapadi dapat meningkatkan produksi tanaman padi dan ikan, mengurangi biaya peyiangan gulma/ matun, mengurangi penggunaan pupuk, mampu meningkatkan pendapatan dan mencukupi kebutuhan sehari-hari serta meningkatkan keterampilan dan pengalaman dalam berusahatani.

Partisipasi pada tahap evaluasi yaitu keterlibatan petani dalam memberikan penilaian atau tanggapan dalam penerapan minapadi. Partisipasi petani pada tahap evaluasi dalam penerapan minapadi tergolong dalam kategori tinggi mencapai $35,82 \%$ atau dengan jumlah 24 orang. Partisipasi petani pada tahap evaluasi dalam penerapan minapadi tergolong dalam kategori tinggi dikarenakan frekuensi penyuluh mengadakan evaluasi dengan petani terkait penerapan minapadi sangat sering dilakukan. Dinas Pertanian juga mengadakan evaluasi dengan petani terkait penerapan minapadi dengan terjun langsung di lahan minapadi para petani.

\section{Faktor-faktor yang Mempengaruhi Partisipasi Petani dalam Penerapan Minapadi Pendidikan Non Formal}

Pendidikan non formal tergolong dalam kategori rendah dengan 33 orang atau 49,25\%. Kegiatan pelatihan maupun penyuluhan yang diselenggarakan oleh Dinas Pertanian hanya perwakilan kelompok dan kegiatan demplot diselenggarakan memusat di salah satu kelompok pembudidaya ikan. Waktu yang dimiliki petani terbatas karena petani memiliki pekerjaan utama selain bertani. Pengalaman tergolong dalam kategori rendah dengan persentase $38,80 \%$ atau 26 orang. Banyak petani yang berumur masih muda sehingga belum banyak memiliki pengalaman dalam berusahatani.

Pendapatan rumah tangga tergolong dalam kategori sangat rendah mencapai $41,79 \%$ atau 28 orang. Luas lahan sawah yang diusahakan petani relatif sempit sehingga hasil ikan maupun padi yang diperoleh petani tidak banyak dan mengalami kerugian akibat serangan hama. Luas lahan sawah tergolong dalam kategori sangat rendah mencapai $53,73 \%$ atau 36 orang. Luas sawah yang dimiliki petani masuk dalam kategori sangat rendah dengan luasan 500-2000 $\mathrm{m}^{2}$. Setiap kelompok mengusahakan minapadi dengan luasan $10.000 \mathrm{~m}^{2}$, untuk pembagiannya diserahkan pada kelompok.

Keseluruhan dinamika kelompok tergolong dalam kategori sedang dengan jumlah 37 orang atau 55,22\%. Dinamika kelompok tergolong dalam kategori sedang berarti tujuan 
kelompok tinggi, struktur kelompok tinggi, fungsi tugas sedang, pembinaan dan pemeliharaan kelompok sedang, kekompakan kelompok tinggi, suasana kelompok tinggi, tekanan kelompok sangat rendah, keefektifan kelompok sangat tinggi dan agenda terselubung tinggi dan sedang. Lingkungan usahatani terdapat di hulu dan hilir. Daerah hulu untuk ketersediaan air melimpah, kondisi tanah berpasir dan lahan sawah berupa terasering. Daerah hilir untuk ketersediaan air melimpah, kondisi tanahnya relatif berlempung dan lahan sawah berupa hamparan.

Pengaruh Pendidikan Non Formal, Pengalaman, Pendapatan Rumah Tangga, Luas Sawah, Dinamika Kelompok, Lingkungan Usahatani terhadap Partisipasi Petani dalam Penerapan Minapadi

\section{Uji Parsial (Uji t)}

Tabel 2. Hasil Uji t terhadap Variabel Y

\begin{tabular}{lcc}
\hline \multirow{2}{*}{ Model } & \multicolumn{2}{c}{ Unstandardized Coefficient } \\
\cline { 2 - 3 } & P value & Keterangan \\
\hline (Constant) & 0,002 & Signifikan \\
Pendidikan Non Formal (X1) & 0,020 & Signifikan \\
Pengalaman (X2) & 0,748 & TidakSignifikan \\
PendapatanRumahTangga(X3) & 0,045 & Signifikan \\
LuasLahanSawah (X4) & 0,927 & TidakSignifikan \\
DinamikaKelompok (X5) & 0,000 & Signifikan \\
LingkunganUsahatani (D1) & 0,604 & TidakSignifikan \\
\hline
\end{tabular}

Sumber : Analisis Data Primer, 2019

\section{Pengaruh Pendidikan Non formal $\left(\mathrm{X}_{1}\right)$ terhadap Partisipasi Petani}

Nilai $p$ value pada variabel pendidikan non formal $\left(\mathrm{X}_{1}\right)$ sebesar 0,020 menunjukkan $p$ value $\leq \alpha$ atau $0,020 \leq 0,05$ maka $\mathrm{H}_{0}$ ditolak dan $\mathrm{H}_{\mathrm{a}}$ diterima. Hal ini berarti pendidikan non formal secara parsial memiliki pengaruh signifikan terhadap partisipasi petani. Hal ini sesuai dengan hasil penelitian dari Munfaati (2017) yang menunjukkan bahwa semakin banyak kegiatan pendidikan non formal yang diikuti oleh petani maka petani tersebut akan semakin aktif dalam mengikuti kegiatan dalam suatu program dan lebih mudah menerima inovasi atau sesuatu hal yang baru yang diberikan. Kesempatan petani dalam memperoleh pendidikan sangat terbatas, karena ketika ada kegiatan pelatihan atau penyuluhan dari Dinas Pertanian hanya perwakilan kelompok dan kegiatan demplot berlokasi jauh dari tempat petani.

\section{Pengaruh Pengalaman $\left(\mathrm{X}_{2}\right)$ terhadap Partisipasi Petani}

Nilai $p$ value pada variabel pengalaman $\left(\mathrm{X}_{2}\right)$ sebesar 0,748 menunjukkan $p$ value $>\alpha$ atau $0,748>0,05$ maka $\mathrm{H}_{0}$ diterima dan $\mathrm{H}_{\mathrm{a}}$ ditolak. Hal ini berarti pengalaman secara parsial tidak berpengaruh signifikan terhadap partisipasi petani. Sesuai dengan pernyataan Lubis (2000) bahwa semakin muda umur petani maka semakin semangat untuk mengetahui hal baru, sehingga mereka berusaha untuk lebih cepat melakukan adopsi inovasi. Pengalaman petani tergolong rendah dikarenakan banyak petani yang berumur masih muda sehingga belum banyak memiliki pengalaman dalam berusahatani. Hal ini dikarenakan semakin muda umur petani biasanya memiliki semangat ingin tahu apa yang ingin diketahui. 
Pengaruh Pendapatan Rumah Tangga $\left(X_{3}\right)$ terhadap Partisipasi Petani

Nilai $p$ value pada variabel pendapatan rumah tangga $\left(\mathrm{X}_{3}\right)$ sebesar 0,045 menunjukkan $p$ value $\leq \alpha$ atau $0,045 \leq 0,05$ maka $\mathrm{H}_{0}$ ditolak dan $\mathrm{H}_{\mathrm{a}}$ diterima. Hal ini berarti pendapatan rumah tangga secara parsial memiliki pengaruh signifikan terhadap partisipasi petani. Sejalan dengan penelitian Sulistriyanti (2015) bahwa tinggi rendahnya pendapatan maka akan mempengaruhi tinggi rendahnya partisipasi. Mayoritas petani berpendapatan sangat rendah karena mayoritas petani juga mengalami kerugian karena luas lahan yang diusahakan petani relatif tidak luas dan beberapa petani tidak sebagai pemilik lahan sawah tersebut. Serangan hama sering terjadi sehingga menurunkan hasil produktivitas ikan dan padi.

\section{Pengaruh Luas Lahan Sawah $\left(\mathbf{X}_{4}\right)$ terhadap Partisipasi Petani}

Nilai $p$ value pada variabelluas penguasaan sawah $\left(\mathrm{X}_{4}\right)$ sebesar 0,927 menunjukkan $p$ value $>$ $\alpha$ atau $0,927>0,05$ maka $\mathrm{H}_{0}$ diterima dan $\mathrm{H}_{\mathrm{a}}$ ditolak. Hal ini berarti luas lahan sawah secara parsial tidak berpengaruh signifikan terhadap partisipasi petani. Hal ini sejalan dengan penelitian Rizki (2017) menunjukkan petani yang memiliki luas lahan yang terbatas akan cenderung untuk mengembangkan usahataninya. Mayoritas petani memiliki lahan sawah rendah antara 500-2000 $\mathrm{m}^{2}$. Setiap kelompok mengusahakan minapadi dengan luasan $10.000 \mathrm{~m}^{2}$. Petani yang memiliki lahan sawah yang luas rata-rata tidak hanya membudidayakan padi tetapi juga budidaya sayur maupun buah

\section{Pengaruh Dinamika Kelompok $\left(\mathrm{X}_{5}\right)$ terhadap Partisipasi Petani}

Nilai $p$ value pada variabel dinamika kelompok $\left(\mathrm{X}_{5}\right)$ sebesar 0,000 menunjukkan $p$ value $\leq \alpha$ atau $0,000 \leq 0,05$ maka $\mathrm{H}_{0}$ ditolak dan $\mathrm{H}_{\mathrm{a}}$ diterima. Hal ini berarti dinamika kelompok secara parsial memiliki pengaruh signifikan terhadap partisipasi petani.Sesuai dengan penelitian Hermanto dan Swastika (2011) bahwa meningkatnya partisipasi anggota kelompok akan meningkatkan kedinamisan kelompok. Meskipun fungsi tugas, pembinaan dan pemeliharaan kelompok tergolong sedang tetapi tujuan kelompok, struktur kelompok, kekompakan kelompok, suasana kelompok, keefektifan kelompok, agenda terselubung tergolong tinggi serta tekanan kelompok tergolong sangat rendah dapat mempengaruhi partisipasi petani dalam penerapan minapadi.

\section{Uji Koefisiensi Determinasi $\left(\mathbf{R}^{2}\right)$}

Tabel 3. Hasil Uji Model Summary

\begin{tabular}{lcc}
\hline Model & $R$ Square & Adjusted $R$ Square \\
\hline 1 & 0,516 & 0,468 \\
\hline
\end{tabular}

Sumber : Analisis Data Primer 2019

Nilai $\mathrm{R}^{2}$ adalah 0,468 yang berarti variabel independen (pendidikan non formal, pengalaman, pendapatan rumah tangga, luas lahan sawah, dinamika kelompok, Dummy lingkungan usahatani) dapat menjelaskan variabel dependen (partisipasi petani dalam penerapan minapadi) sebesar 46,8\%. Sisanya adalah 53,2\% diterangkan oleh faktor-faktor lain yang tidak diteliti.

\section{Perbedaan Partisipasi Petani Berdasarkan Lingkungan Usahatani dalam Penerapan Minapadi di Kabupaten Sleman}

\section{Pengaruh Dummy Lingkungan Usahatani $\left(D_{1}\right)$ terhadap Partisipasi Petani}

Nilai $p$ value pada variabel Dummy lingkungan usahatani $\left(D_{1}\right)$ sebesar 0,604 menunjukkan $p$ value $>\alpha$ atau $0,604>0,05$ maka $\mathrm{H}_{0}$ diterima dan $\mathrm{H}_{\mathrm{a}}$ ditolak. Hal ini berarti variabel Dummy lingkungan usahatani secara parsial tidak berpengaruh signifikan terhadap partisipasi petani. Partisipasi petani di daerah hulu dan di daerah hilir tidak terdapat perbedaan, walaupun daerah hulu dan daerah hilir memiliki karakteristik yang berbeda. Penelitian Tenriawaruwaty 
(2017) menjelaskan bahwa kondisi lingkungan dapat memberikan pengaruh cukup besar bagi kelancaran pada tahap pelaksanaan. Hal ini karena di daerah hulu dan hilir untuk ketersediaan air cukup karena sepanjang tahun air terus mengalir.

\section{KESIMPULAN DAN SARAN}

\section{Kesimpulan}

Berdasarkan hasil pembahasan maka dapat diambil kesimpulan bahwa partisipasi petani dalam penerapan minapadi di Kabupaten Sleman dapat dilihat dari tahap perencanaan, pelaksanaan, pemanfaatan hasil dan evaluasi menunjukkan bahwa partisipasi petani pada kategori sedang. Faktor-faktor yang mempengaruhi partisipasi seperti pendidikan non formal, pengalaman, pendapatan rumah tangga, luas lahan sawah, dinamika kelompok dan lingkungan usahatani dapat berpengaruh secara signifikan secara bersama-sama terhadap partisipasi petani dalam penerapan minapadi. Secara parsial pendidikan non formal, pendapatan, dinamika kelompok berpengaruh signifikan terhadap partisipasi petani dalam penerapan minapadi. Pengalaman, luas lahan sawah dan lingkungan usahatani tidak berpengaruh signifikan terhadap partisipasi petani dalam penerapan minapadi. Perbedaan partisipasi petani dalam penerapan minapadi di Kabupaten Sleman berdasarkan lokasi, tidak terdapat perbedaan partisipasi petani dalam penerapan minapadi antara daerah hulu dan daerah hilir.

\section{Saran}

Berdasarkan hasil penelitian maka sosialisasi dan pelatihan perlu dilakukan secara intensif terhadap seluruh petani sehingga tidak hanya perwakilan beberapa anggota yang datang namun diharapkan satu kelompok dapat melakukan secara rutin per bulan. Memberikan bantuan permodalan melalui kelompok, sehingga petani tidak merasa kesulitan dalam mencari modal dan petani dapat menerapkan minapadi sepanjang musim. Beberapa metode budidaya minapadi belum semuanya dilakukan, sehingga perlu untuk dikembangkan dan diterapkan di kawasan yang memiliki potensi baik seperti budidaya udang galah dan padi (UGADI), budidaya udang galah, gurame dan padi (UGAMEDI), budidaya lele dan padi (LEDI) serta budidaya udang galah, koi dan padi (UGAKODI).

\section{DAFTAR PUSTAKA}

Badan Pusat Statistik. 2015. Kabupaten Dalam Angka 2016. https://bps.go.id/. Diakses pada 19 Agustus 2018.

Badan Pusat Statistik. 2017. Kabupaten Dalam Angka 2017. https://bps.go.id/. Diakses pada 19 Agustus 2018.

Dinas Pertanian Daerah Istimewa Yogyakarta. 2017. Data Penurunan Luas Lahan Sawah DIY. Daerah Istimewa Yogyakarta.

Dinas Pertanian, Pangan, dan Perikanan Kabupaten Sleman. 2017. Profil Perikanan Kabupten Sleman. Kabupaten Sleman.

Hermanto dan Dewa K.S. Swastika, D. 2011. Penguatan Kelompok Tani: Langkah Awal Peningkatan Kesejahteraan Petani. Jurnal Analisis Kebijakan Pertanian Volume 9 No 4 : 371-390.

Lubis, S. N. 2000. Adopsi Teknologi dan FaktorFaktor yang Mempengaruhinya. USU Press. Medan.

Munfati, N. 2017. Partisipasi Petani dalam Program Seribu Hektar Sistem Tanam Padi Jajar Legowo di Kecamatan Karangpandan Kabupaten Karanganyar.Jurnal Agritexts Volume 41 No $1: 43-54$.

Rizki, D. 2017. Analisis Pendapatan Usahatani Minapadi di Desa Margoluwih Kecamatan Seyegan Kabupaten Sleman. Skripsi. Institut Pertanian Bogor.

Sulistriyanti, F. 2015. Analisis Faktor-Faktor Yang Mempengaruhi Partisipasi Kerja Perempuan Nikah Di Kota Pekanbaru. Jurnal Fekon Volume 2 No 2 : 1-12.

Tenriawaruwaty A, Rukmana D, Salman D. 2017. Partisipasi Masyarakat dalam Pengelolaan Sumberdaya Air Secara Berkelanjutan di Kabupaten Bulukamba. Universitas Hasanuddin. Makasar. 